\title{
Penggunaan Karbon Aktif yang Teraktivasi Asam Phosphat pada Limbah Cair Industri Krisotil
}

\author{
Application Of Activated Carbon With Acid Phosphat Activation On \\ Chrysotile Industrial Wastewater
}

\author{
Rieke Yuliastuti \\ Balai Riset dan Standardisasi Industri Surabaya \\ Kementrian Perindustrian \\ Surabaya, Indonesia \\ riekeyuliastuti@yahoo.com
}

\author{
Handaru Bowo Cahyono \\ Balai Riset dan Standardisasi Industri Surabaya \\ Kementrian Perindustrian \\ Surabaya, Indonesia \\ handaru_bc@yahoo.com
}

\begin{abstract}
Abstrak- Karbon aktif merupakan arang padat yang telah diproses lebih lanjut / diaktivasi, sehingga memiliki sifat daya serap. Proses aktivasi dapat dilakukan melalui aktivasi kimia, diantaranya menggunakan asam Chlorida $(\mathrm{HCl})$ ataupun asam Phosphat $\left(\mathrm{H}_{3} \mathrm{PO}_{4}\right)$. Namun efektifitas penyerapannya nantinya tergantung pula pada material yang akan diserap. Tujuan penelitian ini adalah untuk melihat kemampuan karbon aktif dalam menurunkan kadar COD dan TSS dalam limbah cair industri krisotil setelah diaktivasi dengan Asam Phospat atau Asam Chlorida. Telah dilakukan penelitian untuk melihat kemampuan karbon aktif yang teraktivasi asam phosphat atau asam chlorida dalam menurunkan kadar COD dan TSS dalam limbah cair industri krisotil. Hasilnya adalah karbon aktif yang telah diaktivasi dengan asam phosphat lebih unggul yaitu menurunkan COD teroptimum hingga $63 \%$ pada konsentrasi 5 gr/l dengan biaya pengolahan Rp. 265,5 / liter limbah. Sedangkan untuk karbon aktif yang telah teraktivasi dengan asam chlorida hanya mampu menurunkan COD sebesar $49 \%$ pada kosentrasi $15 \mathrm{gr} / \mathrm{l}$ dengan biaya pengolahan Rp.733,5 / liter limbah.
\end{abstract}

Kata Kunci - karbon aktif, asam phosphat, asam chlorida, limbah cair industri krisotil

Abstract-. Activated carbon is a solid charcoal that has been further processed, so it has the properties of absorption. The activation process can be carried out through chemical activation, including using Chloride acid $(\mathrm{HCl})$ or Phosphate acid (H3PO4). But its absorption ability depends on the material to be absorbed. The purpose of this study was to look at the ability of activated carbon in reducing COD and TSS levels in krisotil industrial wastewater after activation with Acid Phosphate or Chloride Acid. A study has been conducted to examine the activated activated carbon capability of phosphoric acid or chloride acid in lowering COD and TSS levels in the industrial effluents of krisotil. The result is activated carbon that has been activated with phosphoric acid is superior that is reducing the COD to $63 \%$ at a concentration of $5 \mathrm{gr}$ / l with processing costs $R p .265 .5$ / liter of waste. As for activated carbon that has been activated with chloride acid can only reduce COD by $49 \%$ at $15 \mathrm{gr} / \mathrm{l}$ concentration with processing cost Rp.733,5/liter of waste.

Keywords - asbestos industry, wastewater, adsorben, flocculant

\section{PENDAHULUAN}

Karbon aktif merupakan arang padat yang telah diproses lebih lanjut, sehingga memiliki sifat daya serap. Kemampuan serap ditimbulkan karena terbentuknya pori-pori pada arang tersebut akibat proses karbonisasi yang dilanjutkan dengan proses aktivasi. Mutu permukaan arang aktif yang dihasilkan sangat bergantung pada bahan baku, bahan pengaktif, suhu dan cara pengaktifannya ${ }^{[1]}$. Pada proses aktivasi arang aktif terdapat dua cara yaitu melalui aktivasi secara fisik dan kimia. Aktivasi fisik dilakukan dalam dua tahap, tahap pertama karbonisasi dan kedua aktivasi, sedangkan aktivasi secara kimia, bahan diimpregnasi terlebih dahulu dengan bahan pengaktif kemudian dikarbonisasi ${ }^{[1]}$. Aktivasi secara kimia merupakan proses pemutusan rantai karbon dari senyawa organik dengan pemakaian bahan-bahan kimia ${ }^{[2]}$. Aktivasi secara kimia biasanya menggunakan bahan-bahan pengaktif seperti garam kalsium klorida $\left(\mathrm{CaCl}_{2}\right)$, magnesium klorida $\left(\mathrm{MgCl}_{2}\right)$, seng klorida $\left(\mathrm{ZnCl}_{2}\right)$, natrium hidroksida $(\mathrm{NaOH})$, natrium karbonat $\left(\mathrm{Na}_{2} \mathrm{CO}_{3}\right)$ dan natrium klorida $(\mathrm{NaCl})$. Selain garam mineral biasanya digunakan ialah berbagai asam dan basa organik seperti asam sulfat $\left(\mathrm{H}_{2} \mathrm{SO}_{4}\right)$, asam klorida $(\mathrm{HCl})$, asam hipoklorit $(\mathrm{HClO})$, kalium hidroksida $(\mathrm{KOH})$, dan natrium hidroksida $(\mathrm{NaOH})$. Bahan-bahan pengaktif tersebut berfungsi untuk mendegradasi atau penghidrasi molekul organik selama proses karbonisasi, membatasi pembentukan tar, membantu dekomposisi senyawa organik pada aktivasi berikutnya, dehidrasi air yang terjebak dalam rongga-rongga karbon, membantu menghilangkan endapan hidrokarbon yang dihasilkan saat proses karbonisasi dan melindungi permukaan karbon sehingga kemungkinan terjadinya oksidasi dapat dikurangi ${ }^{[2]}$.

Pada umumnya industri dan masyarakat menggunakan karbon/arang aktif sebagai bahan pembersih, dan penyerap, juga digunakan sebagai bahan katalisator. Sedangkan pada sistem pengolahan limbah cair, karbon aktif digunakan untuk membersihkan air buangan dari pencemar warna, bau, zat beracun, dan logam berat. Mengambil Gas Polutan (pollutant remover), menghilangkan gas beracun, bau busuk, asap, uap air raksa, uap benzen dan lain-lain. Dalam pengolahan air, 
karbon aktif digunakan sebagai adsorben untuk menyisihkan rasa, bau, dan warna yang disebabkan oleh kandungan bahan organik dalam air. Selain itu karbon aktif berfungsi sebagai filter untuk menjernihkan air, pemurnian gas, industri minuman, farmasi, katalisator,dan berbagai macam penggunaan lain ${ }^{[3]}$.

Prinsip kerja karbon aktif dalam pengolahan limbah adalah dengan adsorpsi sehingga terjadi penggumpalan subtansi terlarut yang ada dalam larutan (adsorbat) oleh permukaan benda atau zat penyerap (adsorben). Mekanisme yang terjadi adalah molekul adsorben berpindah dari fase terbesar ke permukaan antara adsorben yaitu lapisan film yang melapisi permukaan adsorben, molekul-molekul adsorben berpindah dari permukaan antara adsorben kepermukaan luar, molekulmolekul adsorbat berpindah dari permukaan luar adsorben, dimana molekul tersebut menyebar menuju pori-pori adsorben, molekul-molekul adsorbat menempel pada permukaan poripori adsorben, molekul-molekul adsorbat menempel pada permukaan pori-pori adsorben.

Beberapa penelitian yang telah dilakukan untuk meningkatkan kinerja karbon aktif dan pemanfaatnya di industri, diantaranya lama aktivasi pada arang aktif serbuk gergaji sengon yang paling optimum adalah 90 menit pada suhu $850^{\circ} \mathrm{C}^{[4]}$, sedangkan Darmawan 2009 membuat karbon aktif dari tempurung kemiri dengan mengaktivasinya dengan asam phosphat pada suhu $800^{\circ} \mathrm{C}$ selama 120 menit $^{[1]}$. Setelah proses aktivasi tersebut, maka karbon aktif bersifat sangat aktif dan akan menyerap apa saja yang kontak dengan karbon tersebut.

Pada limbah cair industri berbasis krisotil, limbah berasal dari proses pengepresan/ pencetakan. Adanya bahan baku yang ditambahkan seperti krisotil, semen, kertas, kaolin mengakibatkan limbah yang dihasilkan bersifat basa $(>12)$, COD tinggi (>1400 mg/l), TSS tinggi (> $1500 \mathrm{mg} / \mathrm{l})$.

Tujuan penelitian ini adalah untuk melihat kemampuan karbon aktif dalam menurunkan kadar COD dan TSS dalam limbah cair setelah diaktivasi dengan Asam Phospat atau Asam Chlorida.

Ruang lingkup penelitian dibatasi pada karbon aktif yang digunakan berasal dari bahan tempurung kelapa yang belum diaktivasi dan bahan aktivasi yang digunakan adalah asam phosphat sebagai pembanding adalah asam chlorida. Produk aktivasi karbon aktif tersebut digunakan untuk menurunkan kadar COD dan TSS limbah cair industry krisotil yang telah diendapkan.

\section{METODOLOGI}

\section{Cara Aktivasi Karbon Aktif}

1. Uji coba penelitian dengan variabel : menggunakan karbon aktif teraktivasi Asam pospat dan karbon aktif yg teraktivasi $\mathrm{HCl}$

Alat dan Bahan :

- Karbon aktif tempurung kelapa yang belum teraktivasi

- Aktivator : Asam Phosphat $\left(\mathrm{H}_{3} \mathrm{PO}_{4}\right)$, Asam Chlorida $(\mathrm{HCl})$

- Tanur
Metode :

Karbon aktif yang belum teraktivasi direndam dalam larutan asam phosphat teknis sebanyak $10 \%$ (b/v) selama 24 jam. Arang tersebut kemudian ditiriskan dan diaktivasi menggunakan tanur selama 90 menit pada suhu $850^{\circ} \mathrm{C}$ sebagai pembanding adalah direndam dengan menggunakan asam chlorida $(\mathrm{HCl})$. Karbon yang telah aktif tersebut didiamkan sehari kemudian digunakan untuk mengolah limbah cair industri krisotil.

2. Penggunaan Karbon Aktif Teraktivasi Pada Limbah Cair Alat dan Bahan :

- Karbon Aktif teraktivasi Asam Phosphat (A), Karbon aktif teraktivasi Asam Klorida (B)

- Jartest

- Bekerglas 2 liter

Metode :

Metode penelitian yang dilakukan adalah secara ekperimental laboratorium. Variasi berat karbon aktif dari kedua varian (A) dan (B) masing-masing yang ditambahkan adalah 5 gram/l, 7,5 gram/l, 10 gram/1, 15 gram/l. Dari hasil penelitian dipilih jenis karbon aktif terbaik dari efisiensi pengolahan. Kemudian di cari waktu pengolahan teroptimum dengan variasi pengadukan 0,5 jam, 1 jam, 2 jam dan 3 jam.

\section{HASIL DAN PEMBAHASAN}

Dari hasil pengamatan secara visual terhadap warna karbon aktif yang telah teraktivasi oleh Asam phospat maupun $\mathrm{HCl}$ tidak menunjukkan perbedaan, keduanya tetap berwarna hitam pekat. Setelah diaktivasi tersebut maka karbon aktif telah siap digunakan untuk mengolah limbah cair industri krisotil.

Secara visual, limbah industri krisotil tampak berwarna coklat muda dan terdapat serpihan atau flok-flok. Maka untuk mempermudah proses pengolahan dan menghilangkan pengganggu, limbah diolah secara fisika dulu yaitu dengan pengendapan selama 2 hari. Hasilnya secara visual, terdapat endapan sludge pada dasar dan secara kimia COD turun hingga $742 \mathrm{mg} / \mathrm{l}$ dari COD awal sebesar $1409 \mathrm{mg} / \mathrm{l}$ sedangkan TSS menjadi $143 \mathrm{mg} / \mathrm{l}$ dari besaran $1532 \mathrm{mg} / \mathrm{l}$.

Selanjutnya limbah yang telah melalui pretreatment tersebut akan diolah secara kimia dengan menggunakan variasi karbon aktif. Adapun hasil uji coba pada pengolahan limbah cair industri krisotil terlihat pada tabel 1 dan 2 .

TABEL 1 PENGOLAHAN COD DENGAN VARIABEL AKTIVASI KARBON AKTIF

\begin{tabular}{|c|l|l|}
\hline \multirow{2}{*}{$\begin{array}{c}\text { Penambahan } \\
\text { Karbon Aktif } \\
\text { (gram/l) }\end{array}$} & \multicolumn{2}{|c|}{$\begin{array}{c}\text { Hasil Akhir COD } \\
\text { terolah }\end{array}$} \\
\cline { 2 - 3 } & $\mathbf{A}$ & $\mathbf{B}$ \\
\hline 5 & 321,18 & 618,57 \\
\hline 7,5 & 289,8 & 554,3 \\
\hline 10 & 270,69 & 454,4 \\
\hline 15 & 286,84 & 377,22 \\
\hline
\end{tabular}


TABEl 2 PENGOLAHAN TSS DENGAN VARIABEL AKTIVASI KARBON AKTIF

\begin{tabular}{|c|c|c|}
\hline \multirow{2}{*}{$\begin{array}{c}\text { Penambahan } \\
\text { Karbon Aktif } \\
(\text { gram/l) }\end{array}$} & \multicolumn{2}{|c|}{$\begin{array}{c}\text { Hasil Akhir TSS } \\
\text { terolah }\end{array}$} \\
\cline { 2 - 3 } & A & B \\
\hline 5 & 22 & 53 \\
\hline 7,5 & 20 & 20 \\
\hline 10 & 15 & 20 \\
\hline 15 & 10 & 10 \\
\hline
\end{tabular}

Kode A adalah pengolahan limbah dengan menggunakan karbon aktif yang teraktivasi dengan asam phosphat sedangkan kode B adalah pengolahan limbah dengan menggunakan karbon aktif yang teraktivasi dengan asam klorida. Adapun efisiensi pengolahan dapat dilihat pada grafik berikut

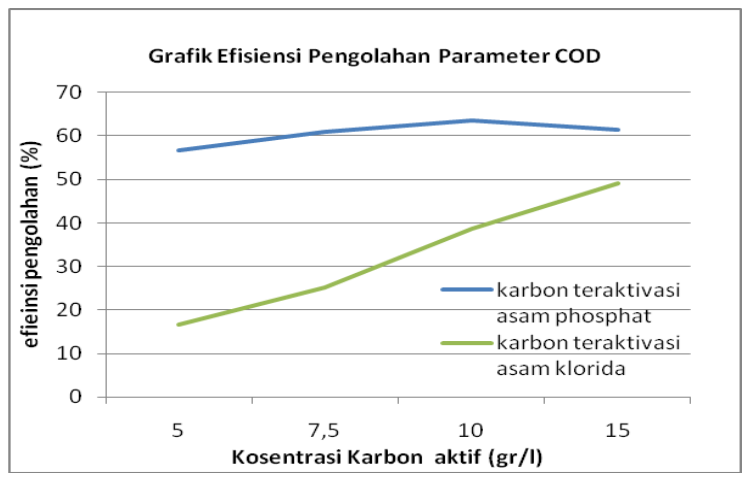

Gambar 1 Grafik Efisiensi Pengolahan Parameter COD dengan variasi karbon aktif teraktivasi

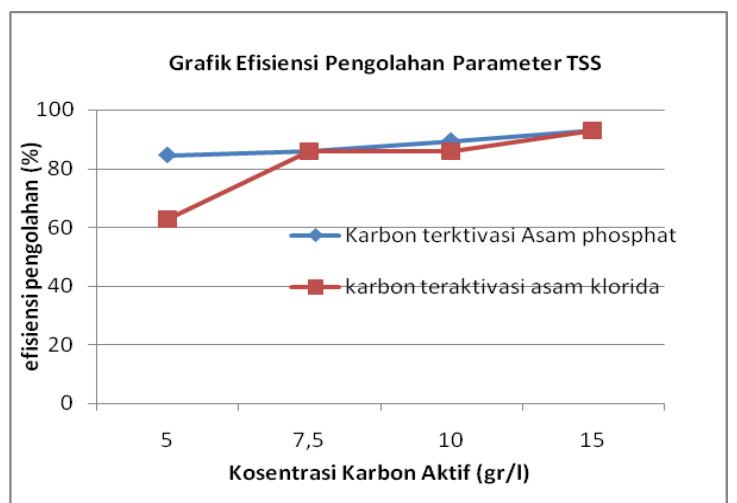

Gambar 2 Grafik Efisiensi Pengolahan Parameter TSS dengan variasi karbon aktif teraktivasi

Dari Grafik tersebut nampak bahwa pengolahan limbah dengan menggunakan karbon aktif yang teraktifasi oleh Asam phosphat (A) hasil akhir COD lebih efisien daripada pengolahan limbah cair menggunakan karbon aktif teraktivasi dengan asam chlorida (B) sehingga hasil akhir COD terolah dengan menggunakan karbon aktif yang teraktivasi asam phosphat dapat memenuhi baku mutu air limbah golongan $2<$ $300 \mathrm{mg} / \mathrm{l}^{[5]}$. Hal ini berlaku pula pada parameter TSS.

Adanya kecenderungan bahwa pengolahan limbah dengan menggunakan karbon aktif yang teraktifasi asam phosphat lebih bagus, dimungkinkan karena terdapat calsium dalam limbah yang berasal dari bahan baku krisotil. Adanya fosfat yang nantinya terperangkap dalam karbon akan bereaksi dengan calsium dalam limbah sehingga membentuk calsium fosfat yang mengendap. Reaksinya adalah sebagai berikut :

$$
2 \mathrm{H}_{3} \mathrm{PO}_{4}+3 \mathrm{Ca}(\mathrm{OH})_{2}-->\mathrm{Ca}_{3}(\ngtr \mathrm{O} 4)_{2}+6 \mathrm{H}_{2} \mathrm{O}
$$

Sedangkan untuk calsium chlorida larut dalam air sehingga penggunaan asam fosfat lebih tepat daripada asam chlorida ${ }^{[6]}$. Adapun nilai calsium yang terdeteksi pada limbah sebagai kesadahan adalah sebesar 1386,97 mg/l.

Lebih lanjut, untuk lebih menyakinkan kinerja karbon aktif yang telah teraktivasi oleh asam phosphat maka dilakukan uji coba dengan variasi waktu pengadukan sebesar 0,5 jam, 1 jam, 2 jam, 3 jam dan kecepatan pengadukan adalah 200 rpm. Hasil penelitian dapat dilihat pada tabel berikut.

TABel 3 PENGOlahan TSS DENGAN VARIABEL AKTIVASI KARBON AKTIF

\begin{tabular}{|c|c|c|c|}
\hline No & $\begin{array}{c}\text { Variasi waktu } \\
\text { pengadukan } \\
\text { (jam) }\end{array}$ & $\begin{array}{c}\text { COD akhir } \\
(\mathbf{m g} / \mathbf{l})\end{array}$ & Efisiensi \\
\hline 1 & 0,5 & 354,66 & 74,7 \\
\hline 2 & 1 & 288,76 & 79,4 \\
\hline 3 & 2 & 298.65 & 78,7 \\
\hline 4 & 3 & 269,13 & 80,8 \\
\hline
\end{tabular}

Pada tabel tersebut tampak bahwa efisiensi penurunan COD tertinggi sebesar $80,8 \%$ dan diraih saat limbah diaduk selama 3 jam. Namun bila dikaji saat waktu pengadukan 1 jam, efisiensi penurunan COD sudah cukup tinggi yaitu sebesar $79,4 \%$ kemudian menurun lagi sebesar 78,7\% dan naik lagi. Hal ini bisa dikatakan bahwa grafik tersebut mulai konstan maka dipilih waktu pengadukan optimal 1 jam yaitu ketika pertama kali efisiensi penurunan COD meninggi

Secara perhitungan rupiah untuk mengolah 1 liter limbah cair industri krisotil adalah sebagai berikut :

a. Biaya Pengolahan limbah dengan karbon aktif dan asam phosphat

Harga karbon aktif $=$ Rp. $45.000 / \mathrm{kg}$

Harga asam phospat teknis $=$ Rp. 81.000/ltr

Untuk mengolah 1 liter limbah, sehingga COD terolah sesuai atau setidaknya hampir memenuhi baku mutu ( \pm $300 \mathrm{mg} / \mathrm{l}$ ) diperlukan karbon aktif teraktivasi phospat sebanyak 5 gram /1. Maka, harga total karbon aktif teraktivasi phosphat $=$ Rp. 265,5

b. Biaya Pengolahan limbah dengan karbon aktif dan $\mathrm{HCl}$

Harga karbon aktif $=$ Rp. $45.000 / \mathrm{kg}$

Harga asam klorida teknis = Rp. 39.000/1tr

Untuk mengolah 1 liter limbah, sehingga COD terolah sesuai atau setidaknya hampir memenuhi baku mutu $( \pm 300$ $\mathrm{mg} / \mathrm{l})$ diperlukan karbon aktif teraktivasi asam klorida sebanyak 15 gram /l. Maka, harga total karbon aktif teraktivasi asam klorida $=$ Rp. 733,5. 


\section{KESIMPULAN}

Telah dilakukan penelitian untuk melihat kemampuan karbon aktif yang teraktivasi asam phosphat atau $\mathrm{HCl}$ dalam menurunkan kadar COD dan TSS dalam limbah cair industri krisotil. Hasil yang dapatkan bahwa untuk mengolah limbah cair industri krisotil maka karbon aktif yang telah diaktivasi dengan asam phosphat lebih unggul yaitu menurunkan COD teroptimum hingga $63 \%$ pada kosentrasi 5 gr/l dibandingkan dengan menggunakan karbon aktif yang teraktivasi asam chlorida efisiensinya $49 \%$ pada kosentrasi 15 gr/l. Adapun biaya pengolahan limbah untuk 1 liter limbah cair industri krisotil. Dengan menggunakan karbon aktif teraktivasi asam phosphat menghabiskan Rp.265,5 / liter limbah sedangkan karbon aktif teraktivasi asam chlorida menghabiskan Rp.733,5 / liter limbah. Adanya kecenderungan bahwa pengolahan limbah dengan menggunakan karbon aktif yang teraktifasi asam phosphat lebih bagus, dimungkinkan karena terdapat calsium dalam limbah yang berasal dari bahan baku krisotil sehingga membentuk calsium fosfat yang mengendap.

\section{DAFTAR PUSTAKA}

[1] Darmawan dkk, 2009, Optimasi Suhu dan Lama Aktivasi Dengan Asam Phosphat Dalam Produksi Arang Aktif Tempurung Kemiri

[2] Khuluk Rifki, 2016, Pembuatan dan Karakterisasi Karbon Aktif Dari Tempurung Kelapa Sebagai Adsorben Zat Warna Metilen Blue, Skripsi, Fakultas matematika dan Ilmu Pengetahuan Alam, Universitas Lampung

[3] Wulandari dkk, 2012, Pengaruh Temperatur Pengeringan Pada Aktivasi Arang Tempurung Kelapa Dengan Asam Klorida dan Asam Fosfat Untuk Penyaringan Air Keruh

[4] Anonim, 2013, Peraturan Gubernur Jawa Timur No. 72 Tahun 2013 Tentang Baku Mutu Air Limbah Bagi Industri dan/atau Kegiatan Usaha lainnya

[5] Pari Gustan, dkk, 2011, Pengaruh Lama Aktivasi Terhadap Struktur Kimia dan Mutu Arang Aktif Serbuk Gergaji Sengon

[6] Perry Robert, Grren Don W, 2008, Perry'S Chemical Engineers Handbook, 8th Edition, Mc Graw Hill 